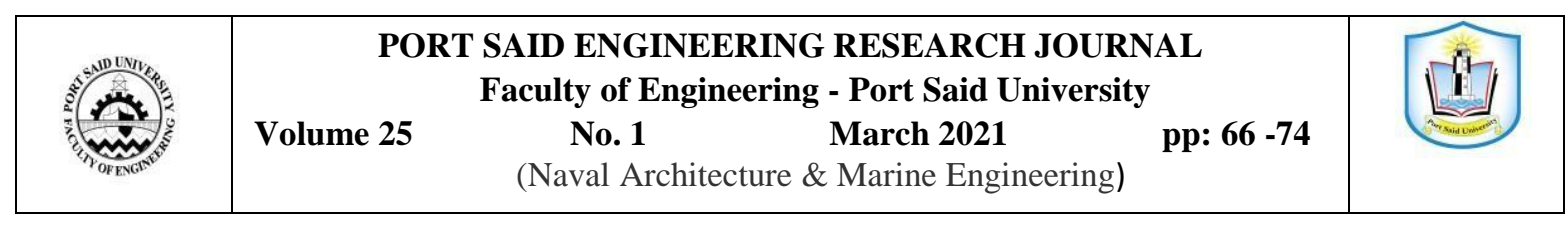

\title{
Motion of Submerged Submarine in the Near Surface of Lateral Waves
}

\author{
M. M. Gaafary ${ }^{1}$
}

Received: 27 May 2020; Accepted: 4 November 2020

\begin{abstract}
A submarine when deeply submerged, hull compression and buoyancy force variation would occur, which suggests a near to surface submergence whenever possible. In addition, a near to surface operation of submerged submarine in lateral waves would have longer natural periods. In this work, the dynamic loads and motion response of low submergence of submarine in lateral waves of deep water are investigated. However, the very low meta-centric height of a submerged submarine has a great and direct effect on the submarine both transverse and longitudinal dynamic instability.

The linear potential theory of deep water flow, together with Froude-Krylov hypothesis on long lateral waves, and proper applications of the strip theory techniques have been applied properly to predict for a submarine lateral sea wave exciting loads of heave, sway, and roll motions at a proper range of wave frequency. A published experimental work on heave motion of circular cross-sections in lateral waves of deep water is utilized to determine the heave exciting force and heave response for these sections. In addition, The strip theory is employed, to determine the resultant integrated submarine's hull heave exciting force and motion response in lateral waves. The results of the present development on submarine heave motion, have good agreement with those based on experiments, especially in the range of low wave frequency. This agreement gives a good source of validation of the present work for low draft submarine heave, sway, and roll motions in the near surface lateral waves.
\end{abstract}

Keywords: Submarine hydrodynamics, wave exciting dynamic loads on submarine, motion and response of submarine in lateral sea waves, and submarine design.

\section{INTRODUCTION}

Navigation of near to surface submerged submarine in a lateral sea condition has from hydrodynamics point of view, some dynamic, safety, and economic advantages;

1- Less dynamic load and lower response amplitudes of sway, roll, and heave motions with longer natural periods, as compared to navigation on sea surface.

2- Less submarine hull compression or change in buoyancy, due to variation of water pressure, salinity, and temperature with water depth.

3- Facilitates and provides more safety for lately proposed arctic LNG transportation, Jacobsen, 1983.

4- Near to surface submergence provides less submarine residual resistance, as compared to sea surface navigation.

\footnotetext{
${ }^{1}$ Department of Naval Architecture and Marine Engineering, Faculty of Engineering, Port Said University, Port Said, Egypt. email:Mo2mengaafary@eng.psu.edu.eg,Corresponding author.
}

In this work, a near to sea surface, submarine dynamic load and motion response, is investigated when operates in lateral waves. This dynamic behavior is somewhat similar to that of a SWATH ship, Eric Haun, 2013 and Lamb, 1988, which has recently achieved a strong growing demand in different marine applications with several and variety of available published research work on its dynamic behavior among

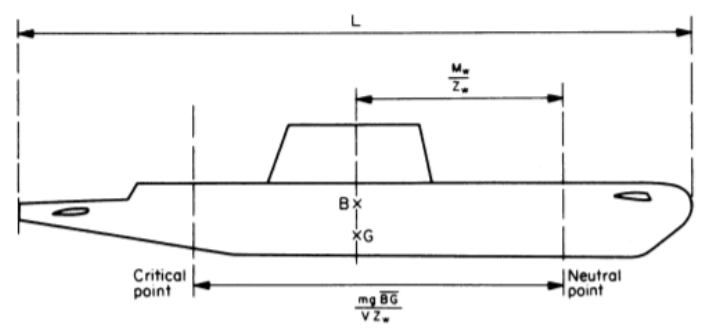

waves.

Figure 1. Submarine diagrammatic arrangement of Series 58 conventional type, showing positions of CG and CB, Rawson, et al, (2004).

However, there are some differences between the two cases, such that:

1-The submarine meta-centric height is relatively smaller. where, the meta-center M lies on the center of buoyancy; $\mathrm{CB}$. Hence, the transverse dynamic stability of a submersible body gets affected with any small disturbance, in the lat- 
eral direction, see figure 1 . However, once the sea wave disturbance stops, the submarine will recover from sway, roll, and heave motions.

2- Submarine's hull is mostly compressible more than sea water hence, diving in the vertical direction will change the buoyancy force, Lamb, 1988.

3- Equilibrium between weight and buoyancy is a difficult task, where, fuel and stores are continuously varying, while ballast tanks must substitute these differences, Lamb, 1988. 4- Continuous application of hydroplanes or elevators together with stabilizers is required to satisfy this task, see figure 2 .

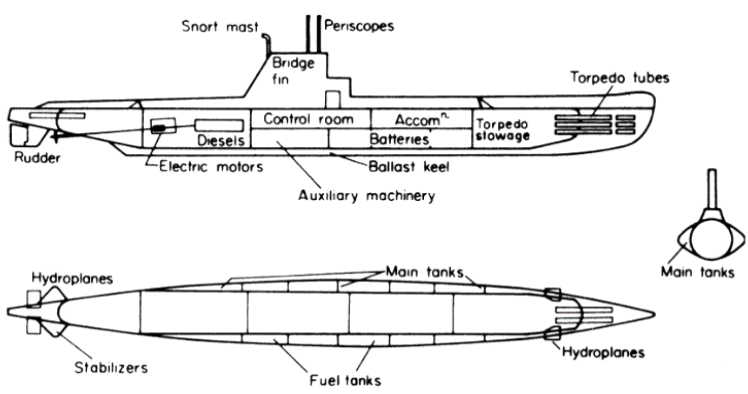

Figure 2. Submarine diagrammatic arrangement of Series 58 conventional type, showing position of hydroplanes and stabilizers application, Rawson, et al, (2004).

Comparing the submerged submarine features and configurations with those of a SWATH ship, Eric Haun, 2013 Lamb, 1988and Butcher Roy, et al, 1994, one may find some basic differences;

- Design, size, and form,

- SWATH has twin pontoons with struts,

- Operating function,

- SWATH has an above water platform,

- Submarine has a relatively longer natural period of heave motions,

- Different magnitudes of wave exciting force and moments of roll, sway, and heave motions and response,

- Different magnitudes of internal sea wave exciting roll, sway, and heave dynamic loads and motions response.

In beam sea condition, the submarine has a relatively short vertical hydro-sail, while in some SWATH ships, they have long vertical struts, which are laid along its submerged pontoons hence, the dynamic loads and motion responses are relatively higher than those of a submarine. Also, the lateral wave encounter has a higher impact load on SWATH struts than on a submarine. Moreover, the submarine might dive more or navigate in a zigzag course as a maneuver to avoid or decrease the magnitude of such effect of lateral waves impact load, Gaafary, 2010.

The target of this paper is to investigate and predict the dynamic loads and motions of a near to surface submerged submarine, when operates in lateral wave condition. Heave, sway, and roll motions are most likely to occur in beam sea condition, especially when LCB = LCG, Lawrence, 1988.
This design requirement will assure no pitch or yaw motions might occur in near surface lateral waves condition.

"There are very few available published work in the literature on the present subject".

\section{HYDRODYNAMICS OF A SUBMA- RINE NEAR SURFACE OF LATER- AL WAVES}

In this investigation, the potential flow linear theory has been applied and considered as a basic background. In addition, the Froude - Krylov hypothesis and the strip theory techniques are applied after making the following assumptions;

1. As the length to beam ratio of a submarine hull is more than six, hence, the pontoon can be treated as a slender body.

2. The submarine sway, roll, and heave motions due to lateral waves are assumed to be uncoupled.

3. Free surface effect is small and negligible, where the submergence ratio of draft to pontoon diameter is about or greater than two.

4. Wave length is assumed to be large as compared to the submarine breadth. Hence, there will be no diffracted waves. 5. As the submerged submarine navigates, the inertia of its hull speed will not allow the hull to radiate waves.

Based on these assumptions, only the incident velocity potential of lateral waves will be effective. This means that there will be no velocity potential due to diffracted or radiated lateral waves.

Therefore, at a proper range of low frequency, the Froude Krylov hypothesis is applied to investigate the incident lateral wave exciting heaving, swaying, and rolling dynamic loads and motions of submerged submarine cross-sections, as shown in figure 3 .

Also, the strip theory can be applied to determine the total wave exciting loads and response of the whole submarine immersed hull, Lawrence, 1988 and Newman, 1980. An experimental work on heave motion of similar crosssections in lateral waves has been employed to determine the heave motion and exciting force for each section, Gaafary, 2010, Frank, 1967 and Kim, 1969. The strip theory is employed, to determine the submerged submarine total heave exciting force and motion response in lateral waves. The present development results agree with those based on experimental testing especially in the range of low wave frequency. However, there is minor difference at submarine natural heave frequency. This agreement of results would give a validation to the present work on submarine motion in lateral waves.

\section{SUBMARINE MOTION RESPONSE IN THE NEAR SURFACE OF LAT- ERAL WAVES}

When a submarine navigates in lateral waves condition, these waves will induce roll, sway and heave dynamic loads 
and hull motions. The velocity potential of the incident beam wave to a submerged submarine can be expressed as;

$\Phi_{I}(x, y, t)=\frac{g a}{\omega} e^{v y} \sin (v x-\omega t)$

$=\Phi_{I}^{(o)}(x, y) \cos (\omega t)+\Phi_{I}^{(e)}(x, y) \sin (\omega t)$

The dynamic pressure due to the incident wave only, can be derived as follows,

$$
\begin{aligned}
P(x, y, t)= & -\rho \frac{\partial \Phi_{I}(x, y, t)}{\partial t} \quad \cdots \\
P(x, y, t)= & \rho g a e^{v y}[\sin (v x) \cdot \sin (\omega t)+ \\
& \cos v x \cdot \cos \omega t
\end{aligned}
$$

let,

$$
\begin{aligned}
& \frac{p^{(o)}(x, y)}{a}=\rho g e^{v y} \sin (v x) \\
& \frac{p^{(e)}(x, y)}{a}=\rho g e^{v y} \cos (v x)
\end{aligned}
$$

Also,

$p(x, y)=\left[p^{(e) 2}(x, y)+p^{(o) 2}(x, y)\right]^{1 / 2}$

Hence, the Froude-Krylov dynamic pressure components and magnitude, acting on each point of cross-section of the immersed body of platform is developed as in equations (4a) and (4-b), and plotted as in figure 3 . Therefore, the total force acting on the total contour of a cross-section can be estimated,

$\overline{\mathrm{F}}_{\text {cross -section }}=-\int_{\mathrm{c}} \overline{\mathrm{n}} \cdot \mathrm{p}(\mathrm{x}, \mathrm{y}) \mathrm{ds}$

The minus sign is because that the unit normal vector $(\bar{n})$ is outward directed vector, while $(\bar{F})$ is directed inward the contour of a pontoon cross-section. Hence, the strip theory technique can now be applied to determine the total force value acting on submarine by integrating the wave elementary force along the pontoon's immersed length,

$\overline{\mathrm{F}}_{\text {Submarine }}=\int_{\mathrm{L}} \overline{\mathrm{F}}_{\text {cross -section }} \cdot \mathrm{dz} \quad \ldots$

Submarine particulars of 8639-LT displacement, as given in Lamb, 1988, are in Table 1.

Table 1: Main Particulars of Submarine,

Series 58 Type, Eric Haun, 2013

$$
\begin{array}{ll}
\text { Effective Diameter } & =10.50 \mathrm{~m} \\
\text { Length } & =100.8 \mathrm{~m}
\end{array}
$$

Hydro-Sail Depth $x$ mean

$$
\begin{array}{ll}
\text { Length } \times \text { mean Width } & =10.5 \mathrm{~m} \times 18 \mathrm{~m} \times 6.0 \mathrm{~m} \\
\text { Draft } & =21 \mathrm{~m} \\
\text { Displacement } & =8639-\mathrm{LT}
\end{array}
$$

$\mathrm{KB} \quad=5.70 \mathrm{~m}$ from keel

$\mathrm{KG} \quad=4.00 \mathrm{~m}$ from keel

$k_{x x}=1.732 \mathrm{~m} \& k_{y y}=5.2 \mathrm{~m}$

$\mathrm{KS}$; center of projected submerged

longitudinal area $\quad=7.3 \mathrm{~m}$

$\mathrm{H}=\mathrm{KS}-\mathrm{KG} \quad=3.3 \mathrm{~m}$
When the incident lateral waves encounter with transverse immersed cross-sections of the submarine hull, the particulars of waves are specified, as in Table 2, Gaafary, 2010.

\section{Table 2: Particulars of incident lateral waves}

- Wave period range; $T_{w}=5,10,15,20,25,30$, and 35 seconds,

- Wave frequency; $\omega=\left(\frac{2 \pi}{T_{w}}\right) \mathrm{radian} / \mathrm{s}$,

- Co-ordinates of different points co-ordinates on submarine pontoon cross-section contours are shown in figure 3 .

The wave length can be determined through the useful expression of the wave dispersion relation that is given as;

$\left[v=\omega^{\wedge} 2 / g\right]$, which relates the wave number to the wave frequency.

\section{SUBMARINE HEAVE MOTION IN THE NEAR SURFACE OF LATER- AL WAVES}

Based on the Froude - Krylov hypothesis, submerged submarine, heave exciting force and heave response are investigated, and determined.

\subsection{Heave Exciting Force in Beam Sea}

The non-dimensional submarine heave exciting force acting on the submarine hull is;

$$
Y_{\text {Sub. }}^{K}=\overrightarrow{F_{\text {Sub }}} \cdot \vec{j}
$$

This Froude - Krylov heave exciting force is produced by the even incident potential. Since the submarine heave motion is symmetric, hence, odd terms of dynamic pressure will cancel each other.

$\mathrm{Y}_{\text {sub }}^{\mathrm{k}}(\mathrm{x}, \mathrm{y}, \mathrm{t})=$

$\mathrm{Y}_{\text {sub . c }}^{\mathrm{k}}(\mathrm{x}, \mathrm{y}) \cos (\omega \mathrm{t})+\mathrm{Y}_{\text {sub . s }}^{\mathrm{k}}(\mathrm{x}, \mathrm{y}) \sin (\omega \mathrm{t})$

but,

$$
\mathrm{Y}_{\text {sub } . ~ s}^{\mathrm{k}}(\mathrm{x}, \mathrm{y})=0
$$

hence,

$\mathrm{Y}_{\text {sub }}^{\mathrm{k}}(\mathrm{x}, \mathrm{y}, \mathrm{t})=\mathrm{Y}_{\text {sub . }}^{\mathrm{k}}(\mathrm{x}, \mathrm{y}) \cos (\omega \mathrm{t})$

Consider the transverse sections of the immersed hull as shown in figure 3 . Therefore, the strip theory technique can be applied on the submarine hull as;

$$
\begin{aligned}
& Y_{\text {sub . } c}^{k}(x, y)=\int_{c} p^{(e)}(x, y) d z \\
& Y_{\text {total }}^{\mathrm{k}}(\mathrm{x}, \mathrm{y}, \mathrm{t})=\mathrm{Y}_{\text {sub . c }}^{\mathrm{k}}\left(\operatorname{cosux}_{\mathrm{o}}\right) \\
& \varepsilon_{\text {sub . } \xi}=\tan ^{-1}\left(\frac{\mathrm{Y}_{\text {sub .s }}^{\mathrm{k}}}{\mathrm{Y}_{\text {sub .c }}^{\mathrm{k}}}\right)
\end{aligned}
$$


$\varepsilon_{\text {sub . }}=0$

Therefore, the submarine heave motion's crest is in phase with the incident lateral beam wave's crest at all wave frequencies. As a result of this work, the distribution of total non-dimensional heave exciting force of submarine in beam sea condition is;

$\left[\frac{Y_{\text {sub. heave }}^{k}}{\text { a LLBT v }}\right]$ Vs. Tw,

Which are developed in this present work on basis of Froude-Krylov hypothesis, and the results are found to agree with the experimental results, these results are then plotted versus wave period, as in figure 4 .

\subsection{Submarine Heave Response in Beam Sea}

The equation of SWATH heave motion in beam sea condition is given by,

$\frac{\bar{Y}_{T}^{k}}{a}=\left[\begin{array}{c}-\omega^{2}\left(M_{o}+M_{\xi \xi}^{\prime \prime}\right) \\ -i \omega N_{\xi \xi}+B_{\xi \xi}\end{array}\right] \frac{\bar{\xi}}{a} \quad \ldots$

Therefore, the submarine heave motion response in beam sea can be developed from (9) as,

$\left|\frac{\bar{\xi}}{a}\right|=\frac{\frac{\bar{Y}_{T}^{k}}{a}}{\left[\left(B_{\xi \xi}-\omega^{2}\left(M_{o}+M_{\xi \xi}{ }^{\prime \prime}\right)\right)^{2}+\left(i \omega N_{\xi \xi}\right)^{2}\right]}$

For potential flow linear theory, the fluid is considered as non-viscous and consequently the damping term will be small and can be neglected. Therefore, the distribution of submarine heave motion in Beam Sea as a response amplitude operator is given by;

$\left[\frac{|\xi|}{a}\right]$ Vs. Tw, is plotted versus the wave period as in figure 5 .

The submarine heave motion natural period is,

$T_{z}=2 \pi \sqrt{\frac{\nabla \cdot\left(1+\alpha_{z Z}\right)}{g \cdot A_{W P}}}=28.3 \mathrm{~s}$

Where, for a submarine heave motion of this type of geometry, Rawson, 1984, it is found that;

$$
\alpha_{z z}=0.7
$$

\subsection{Heave Motion Comparison between Present} Theory and Experimental Results

For submerged cylinders of different geometry, there is some useful experimental work performed by Mc Creight, 1987, Frank, 1967 and Kim, 1969. These performed tests were held in purpose of measuring the heave motions of similar sections when submerged in beam sea condition. These test results were recorded to the basis of (v.T). Hence, the Kim experimental test results are utilized in the present work, to predict the heave exciting force and heave motion parameters for each submarine transverse section. Finally, the strip theory technique has been applied to determine the submarine total heave exciting force, and heave motion response operator. The present method results of submarine heave exciting force and heave response have good agreement with those based on experimental results, especially in the range of low frequency, with minor differences at natural heave period. Therefore, the present work results on submarine sway and roll motions are expected to have the same agreement with experimental test results.

\section{SUBMARINE SWAY MOTION NEAR TO SURFACE OF LATERAL WAVES}

\subsection{Sway Exciting Force in Beam Sea}

The non-dimensional submarine sway exciting force acting on a submarine is;

$\mathrm{X}_{\text {Sub } .}^{\mathrm{K}}=\overline{\mathrm{F}_{\text {Sub }}} \cdot \overrightarrow{\mathrm{i}}$.

This sway exciting force can be determined for submarine hull, which is symmetric about its centerline. Since the sway motion is asymmetric hence, only the odd terms of Froude Krylov sway exciting force will survive, while the even terms will cancel each other.

$$
\begin{aligned}
& X_{\text {sub. }}^{\mathrm{k}}(\mathrm{x}, \mathrm{y}, \mathrm{t})= \\
& \mathrm{X}_{\text {sub. c }}^{\mathrm{k}}(\mathrm{x}, \mathrm{y}) \cos (\omega \mathrm{t})+\mathrm{X}_{\text {sub . s }}^{\mathrm{k}}(\mathrm{x}, \mathrm{y}) \sin (\omega \mathrm{t}) \\
& \ldots \quad(11-\mathrm{a})
\end{aligned}
$$

But,

$\mathrm{X}_{\text {sub. }}^{\mathrm{k}}(\mathrm{x}, \mathrm{y})=0$

It is an even function, the Froude - Krylov sway exciting force that acts on the whole immersed hull can be determined using the strip theory technique,

$\mathrm{X}_{\text {sub . s }}^{\mathrm{k}}(\mathrm{x}, \mathrm{y})=\int_{\mathrm{L}} \overline{\mathrm{T}} \cdot \overline{\mathrm{F}}_{\text {cross }- \text { section }} \mathrm{dz}$

Hence,

$\mathrm{X}_{\text {total }}^{\mathrm{k}}(\mathrm{x}, \mathrm{y}, \mathrm{t})=\mathrm{X}_{\text {sub } . \mathrm{s}}^{\mathrm{k}}\left(\left[\sin \left(\mathrm{ux}_{\mathrm{o}}\right)\right]\right) \quad \ldots$

The phase angle of sway motion can be determined as;

$\varepsilon_{\text {sub. Sway }}=\tan ^{-1}\left(\frac{\mathrm{X}_{\text {sub .s }}^{\mathrm{k}}}{\mathrm{X}_{\text {sub .c }}^{\mathrm{k}}}\right)$

But,

$\mathrm{X}_{\text {sub } . \mathrm{c}}^{\mathrm{k}}=0$

It is an even function, hence,

$\varepsilon_{\text {sub .Sway }}=-\left(\frac{\pi}{2}\right)$ 
Hence, the submarine sway motion crests are leading the crests of an incident lateral beam waves by $(\pi / 2)$. The distribution of total non-dimensional sway exciting force of submarine in Beam Sea is;

$\left[\frac{X_{\text {sub. sway }}^{k}}{a \gamma L B T v}\right]$ Vs. Tw, as plotted as in figure 6.

\subsection{Submarine Sway Response in Beam Sea}

The sway motion of submarine in beam sea waves has been investigated using potential flow theory, where the fluid is assumed as non-viscous, and consequently the damping force is null. Also, in horizontal sway motion, there is no buoyancy variation, and hence, there will be no restoring force. Therefore, the only surviving term is the submarine virtual mass. Therefore, the equation of sway motion for submarine is,

$$
\begin{aligned}
& {\left[-\omega^{2}\left(M_{o}+M_{\eta \eta}{ }^{\prime \prime}\right)\right] \frac{\bar{\eta}}{a}=\frac{\bar{X}_{T}^{k}}{a}} \\
& \left|\frac{\bar{\eta}}{a}\right|=\frac{\frac{\bar{X}_{T}^{k}}{a}}{\left[-\omega^{2}\left(M_{o}+M_{\eta \eta}{ }^{\prime \prime}\right)\right]}
\end{aligned}
$$

The particulars of submarine 8639-LT and the lateral incident waves have been used as in Tables (1), and (2) and Equation (15-b). Hence, the sway motion of submarine has been developed as a sway response amplitude operator; $\left[\frac{|\eta|}{a}\right]$ Vs. $\mathrm{T}_{\mathrm{w}}$, in beam sea condition and is plotted versus wave period, as in figure 7 .

\section{SUBMARINE ROLL MOTION NEAR TO SURFACE OF LATERAL WAVES}

\subsection{Effect of Wave Slope on Rolling Motion}

During navigation, a submarine is predicted to roll in an incident beam wave. Hence, there would be two combined components of rolling moment. The first one is that generated by the difference in buoyancy force between weather side and leeward side, due to a recognized wave slope, this effect will be small and can be ignored when submarine is fully submerged. The second component is generated from the sway force inducing rolling moment. In this present work, only the second rolling moment will be considered, because of its much larger share of influence.

The equation of damped rolling motion for a submarine among incident wave is,

$$
\frac{\Delta}{g} k_{x x}^{2}\left(1+\alpha_{x x}\right) \ddot{\theta}+N \dot{\theta}+\Delta G B \quad \theta=M^{K}(x, y, t)
$$

Let,

$\theta(x, y, t)=\bar{\theta}(x, y) e^{-i \omega t}$

$M^{K}(x, y, t)=\overline{M^{K}}(x, y) e^{-i \omega t}$
Hence,

$\frac{\left[-\omega^{2} \frac{\Delta}{g} k_{x x}^{2}\left(1+\alpha_{x x}\right)-i \omega N+\Delta \cdot G M_{T}\right] \bar{\theta}=}{M^{K}(x, y)}$

This is the final form of rolling equation of motion. According to [7, and 8], the damping coefficient, $\mathrm{N}$, is very small and given as,

Where,

$$
N=\left[T_{\varphi} K_{1} \Delta G B\right] / \pi^{2}
$$

$$
K_{1} \approx 0.05-0.1
$$

Hence, $\mathrm{N}$ has a small effect in the equation of rolling motion. Also, as the linear potential theory is considered in this work, the fluid is treated as non-viscous and damping term is ignored.

\subsection{Rolling Induced by Sway Force}

In a very similar procedure to that of sway exciting force, the submarine rolling motion is developed. This rolling moment is asymmetric and only the odd terms of FroudeKrylov dynamic pressure will survive and the even terms will cancel each other. The wave exciting rolling moment is produced by the odd sway exciting force. The roll exciting moment induced by swaying force acting on a submarine is,

$$
M_{S u b .}^{k}(x, y, t)=M_{c}^{k}(x, y) \cos \omega t+M_{s}^{k}(x, y) \sin \omega t
$$

Even terms must vanish,

$M_{l c}^{k}(x, y) \cos \omega t=0$

But the sway exciting force is also asymmetric hence, the sway exciting force will induce non-dimensional rolling moment of the form,

$M_{s}^{k}(x, y)=h \cdot X_{s}^{k}(x, y) \quad \ldots$

Where,

$$
X_{S}^{k}(x, y)=\int_{L} \tau \cdot \bar{F}_{\text {cross-section }} d z
$$

For the specified submarine geometry, as in Table 1, where, (h)is defined as the vertical arm of rolling moment induced by sway force.

Making use of equation (18), the rolling moment induced by swaying force can be determined. The strip theory can also be applied on the submarine hull.

The phase angle of rolling motion can be determined as,

$\varepsilon_{\text {Roll-wave }}=\tan ^{-1}\left(\frac{M_{l s}^{k}}{M_{l c}^{k}}\right)$

But,

$M_{l c}^{k}=0 ;$ it is an even function, hence,

$\varepsilon_{\text {Roll-wave }}=-\pi / 2$

Therefore, the SWATH rolling motion is leading the incident wave by $(\pi / 2)$.

The submarine rolling moment due to sway induced rolling moment is derived from the equation of rolling motion as, 


$$
\left.\begin{array}{c}
-\omega^{2} \frac{\Delta}{g} k_{x x}^{2}\left(1+\alpha_{x x}\right)+\Delta . G B \\
\bar{M}_{\text {Total }}(x, y)
\end{array}\right] \bar{\theta}=
$$

Where,

$$
\begin{gathered}
K B=5.7 \mathrm{~m} \\
\mathrm{KG}=4.0 \mathrm{~m} \\
G B=1.7 \mathrm{~m}
\end{gathered}
$$

Therefore, the roll exciting moment has been estimated. The distribution of submarine total roll exciting moment has been developed on basis of Froude-Krylov hypothesis and then plotted versus wave period, as in Figure8, which shows a plot for the following total non-dimensional rolling moment for a submarine in beam sea;

$\left[\frac{M_{\text {Sub } \text {.roll }}^{k}}{\operatorname{arLB} T^{2} v}\right]$ Vs. Tw, as shown in figure 8.

Therefore, substituting the above values into Equation (20), one may get the rolling motion response angle;

$$
\bar{\theta}=\frac{\bar{M}_{S u b} .(x, y)}{\left[-\omega^{2} \frac{\Delta}{g} k_{x x}^{2}\left(1+\alpha_{x x}\right)+\Delta . G B\right]}
$$

Also, based on the submarine geometry and particulars, the rolling period is,

$T_{\Theta}=2 \pi k_{x x} \sqrt{\frac{\left(1+\alpha_{x x}\right)}{g \cdot G B}}=5.812 \mathrm{~s}$

Where,

$$
\alpha_{x x}=0.25
$$

For this type of geometry of submarine in rolling motion, [11].

Therefore, the angular rolling motion response can be determined. Figure 9, shows the submarine roll response operator $\left[\frac{|\theta|}{a}\right]$ versus the wave period. Figure 9 also shows that resonance might occur at a wave period equal to the submarine natural rolling period.

Numata, et al, 1980, recommends having movable fins in order to elongate the rolling period of submerged vehicles. $\mathrm{He}$ also recommends having a recognized difference between rolling and pitching natural periods in order not to have both acting on submarine simultaneously. If this happens, an effect known as corkscrew effect would take place and influence the submarine hull. The submarine pitch motion natural period is,

$T_{\psi}=2 \pi k_{y y} \sqrt{\frac{\left(1+\alpha_{y y}\right)}{g . G B}}=15.01 \mathrm{~s}$

Where,

$\alpha_{y y}=0.4$,

For submarine pitch motion of this type of geometry, [11].

Hence, there is a quite difference between the roll and pitch natural periods, this will make this submarine to avoid the effect of coupled pitch and roll motions, and avoid the corkscrew harmful effect to act on a submarine hull.

\section{ANALYSIS OF THE RESULTS}

In this section some analysis of the present results on submarine motions, could be made as follows;

1- The submarine motions in lateral wave are investigated. The potential flow theory, Froude-Krylov hypothesis, and the strip theory are applied to predict the incident lateral wave dynamic loads acting on submarine inducing heaving, swaying, and rolling motions.

2- For a specific submarine geometry when navigates in incident lateral waves of assumed particulars, these dynamic loads and motion response have been determined at different wave periods.

3- The results of predicted submarine heave exciting force and heave motion response are compared with those based on experimental tests. They are in good agreement especially in the range of low wave frequency, as plotted versus wave periods and shown in figures 4 , and 5 .

4- The submarine sway exciting force and sway motion response have been determined and plotted versus wave periods, as shown in figures 6 , and 7 .

5- The lateral wave induced and sway induced rolling moments have been determined using the principle of linear superposition, and then it is plotted versus wave periods as in figure 8 .

6- The submarine rolling motion response operator has been determined and plotted versus wave periods, as in figure 9 .

7- The submarine natural heave, roll, and pitch periods are determined by $28.3 \mathrm{~s}, 5.8 \mathrm{~s}$, and $15.01 \mathrm{~s}$. These values are similar to existing submarines.

\section{CONCLUSIONS AND RECOMMENDATIONS}

\subsection{Conclusions}

Submarine motion when submerged in the near surface lateral sea waves has been investigated, using the linearized potential flow theory, and the Froude-Krylov hypothesis, expressions for the dynamic loads acting on the submarine hull pontoons' cross-sections have been developed. The strip theory technique is applied to predict the total dynamic loads acting on near to surface submarine submerged hull. For specific particulars and geometry of submarine and lateral incident waves, the induced heaving, swaying, and rolling dynamic loads and motions response have been determined, and the following conclusions are drawn;

1-The predicted results of heave exciting force and motion response for a submarine in lateral sea waves, are very close to those results based on experimental tests, especially in the range of low wave frequency of relatively large wave periods and wave lengths.

2- This might give some kind of validation of the method especially in the case of submarine sway and roll motions and response.

3-Submarine sway exciting force and motion response are developed and plotted at a range of lateral wave periods.

4- Submarine natural heaving, rolling, and pitching periods are determined by $28.3 \mathrm{~s}, 5.8 \mathrm{~s}$, and $15.01 \mathrm{~s}$ respectively. 
These values are typical for a near to surface submarine. However, applications of movable or fixed fins are critically required to control submarine rolling and pitching motions.

5- Making openings in the submarine hydro-sail, will provide a method to neutralize the pressure difference between the leeward and windward sides.

6- The difference between rolling and pitching natural periods will protect submarine from an influence known as corkscrew effect.

\subsection{Recommendations}

1- Watertight secured openings are proposed to be applied to the submarine hydro-sail, in order to neutralize the difference in dynamic or static pressures between both sides of hydro-sail. This will prevent water leveling up on one side of a submarine.

2- Applications of movable or fixed fins are required to reduce and control submarine rolling and pitching motions in beam, head, and oblique seas.

3- It is strongly required to keep rolling and pitching periods apart in order to reduce the coupling effect of both motions.

4- High initial stability is required in both transverse and longitudinal directions to resist rolling and pitching motions.

\section{REFERENCES}

Bucher Roy, and Rydill Louis, 1984. Ocean Technology Series 2, Concepts in Submarine Design, Cambridge, Cambridge University.

Eric Haun, Dec. 2013 New Submarine and SWATH Capabilities for HydroComp NavCad, Posted on Maritime Reporter, MarineLink.Com.

Frank, W., 1967. On the Oscillation of Cylinders in or below the Free Surface of Deep Fluids, Naval Ship Research and Development Center, Report no. 2375.

Gaafary, M.M., Oct. 2010. Dynamic Loads and Response of SWATH Ship in Lateral Waves, 10th Black Sea International Conference on Marine Science and Technologies, Varna, Bulgaria.

Jacobsen, L., et al, Oct. 1983. Transportation of LNG from the Arctic by Commercial Submarine, SNAME, Marine Technology.

Kim, C.H., 1969. Hydrodynamic Forces and Moments for Heaving, Swaying, and Rolling Cylinders, on Water of Finite Depth, Journal of Ship Research, Vol. 13, No. 2.

Lamb, G.R., Oct. 1988. Some Guidance for Hull Form Selection of SWATH Ships, SNAME, Marine Technology Journal.

Lawrence L. Goldberg, 1988. Principles of Naval Architecture, Vol. I, and Vol. III SNAME.

McCreight, K.K., 1987. Assessing the Seaworthiness of SWATH Ships, SNAME Transactions.

Newman, J., 1980 "Marine Hydrodynamics," MIT Press, Cambridge, Massachusetts.

Numata, E., April 1988. Predicting Hydrodynamic Behavior of SWATH Ships, SNAME Section.
Rawson, K.J., and Tupper, E.C., "Basic Ship Theory", Vol.2, Longman, 2004.

\section{NOMENCLATURE}

$\mathrm{A}_{\mathrm{wp}} \quad$ water-plane area,

a wave amplitude,

B breadth, or restoring force,

$B M_{L ; T}$ longitudinal or transverse metacentric radius,

b width of sail,

CB submarine center of buoyancy,

D submarine diameter,

F wave exciting force,

G center of gravity,

$G M_{L ; T}$ Longitudinal transverse meta-

Centric height $=\mathrm{GB}$,

g gravitational constant,

$\mathrm{H}$ wave height,

$\mathrm{h}$ vertical distance of rolling arm,

$\vec{i}, \vec{j}$ unit vectors in $\mathrm{x}-, \mathrm{y}$-directions,

$I_{x x} \quad$ Mass moment of inertia,

$\mathrm{K}$ keel position,

$\mathrm{KB}$ height of $\mathrm{CB}$,

$\mathrm{KG}$ height of $\mathrm{CG}$,

$k_{x x}$ radius of gyration about $\mathrm{x}$-axis,

$\mathrm{L}$ length of submarine,

LCB longitudinal center of buoyancy,

LCG longitudinal center of gravity,

$\mathrm{M}$ roll exciting moment,

$\mathrm{M}_{\mathrm{o}} \quad$ body mass,

M" added mass coefficient,

$\mathrm{N} \quad$ two dimensional damping,

$\bar{n} \quad$ unit normal vector,

s infinitesimal surface mesh,

$\mathrm{T}$ draft, motion, or wave period,

$\mathrm{t}$ time parameter,

$\mathrm{X}$ sway exciting force,

$\mathrm{Y}$ heave exciting force,

$\mathrm{x}, \mathrm{y}$ transverse coordinates,

$\mathrm{z}$ longitudinal coordinate,

$\alpha_{x x}$ roll added mass coefficient,

$\alpha_{y y} \quad$ pitch added mass coefficient,

$\alpha_{z z}$ heave added mass coefficient,

$\Delta \quad$ hull displacement,

$\varepsilon \quad$ phase angle difference,

$\Phi$ velocity potential,

$\eta \quad$ sway response,

$\xi \quad$ heave response,

$\lambda$ wave length,

$u \quad$ wave number,

$\rho \quad$ water density,

$\theta$ rolling angle,

$\omega \quad$ wave frequency. 


\section{Superscripts / Subscripts}

c subscript for contour of transverse section,

e \& o superscript for even and odd terms,

I incident wave subscript,

$\mathrm{K}$ superscript for Froude-Krylov,

S\&C superscript for sine and cosine, (corresponding to odd and even terms).

$\mathrm{T}$ subscript for Transverse.

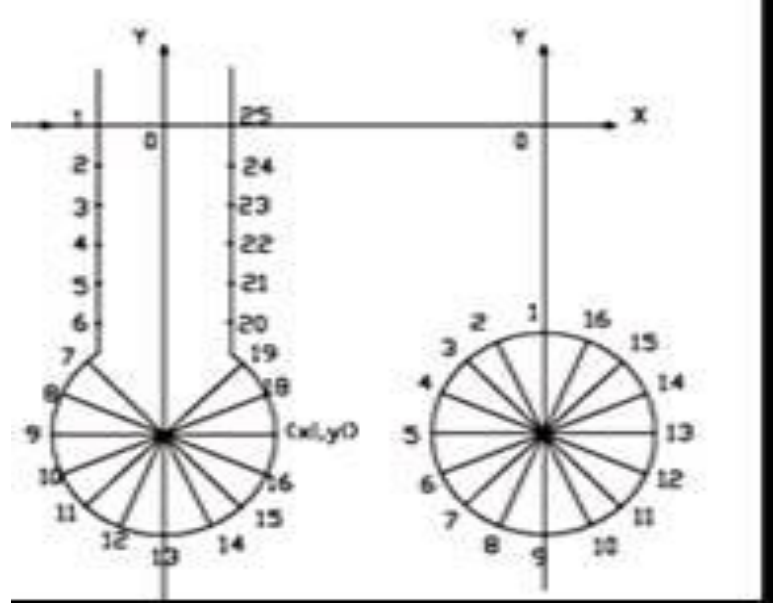

Figure (3): Submarine co-ordinates of contour points on pontoon and sail transverse sections.

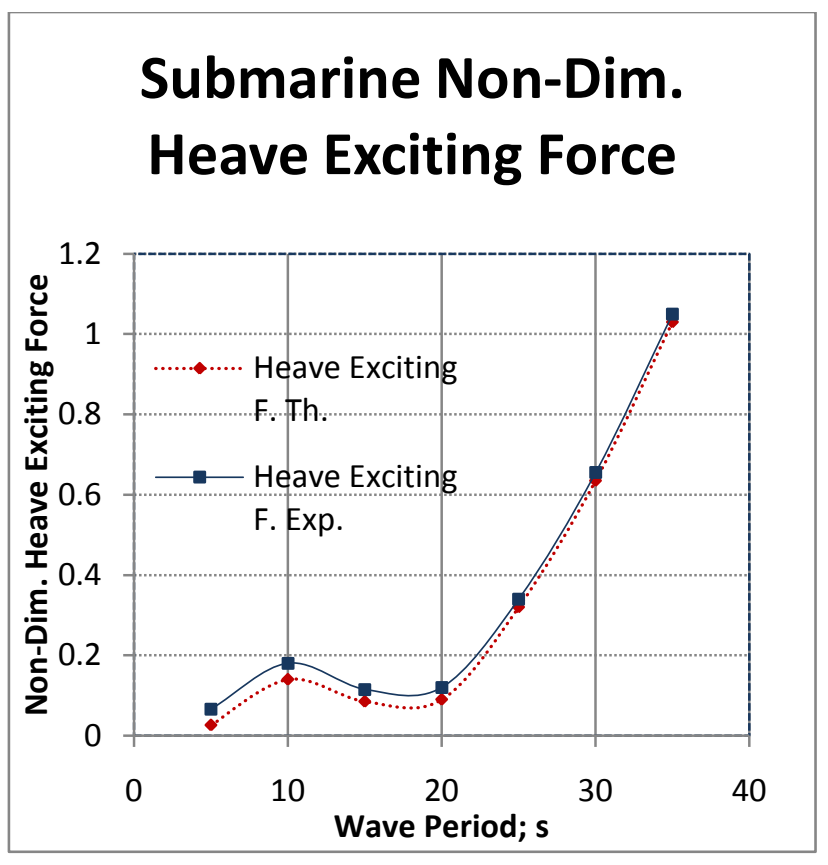

Figure (4): Submarine heave exciting force, in beam-sea, Using present approach.

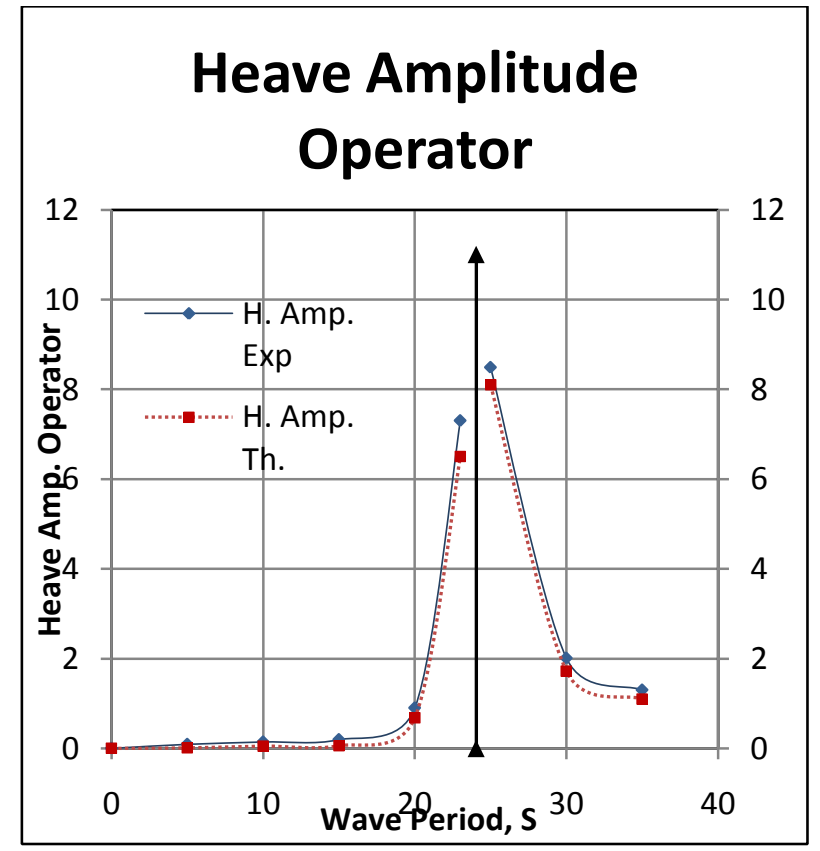

Figure (5): Submarine heave response in beam-sea, using present theory and experimental results. 


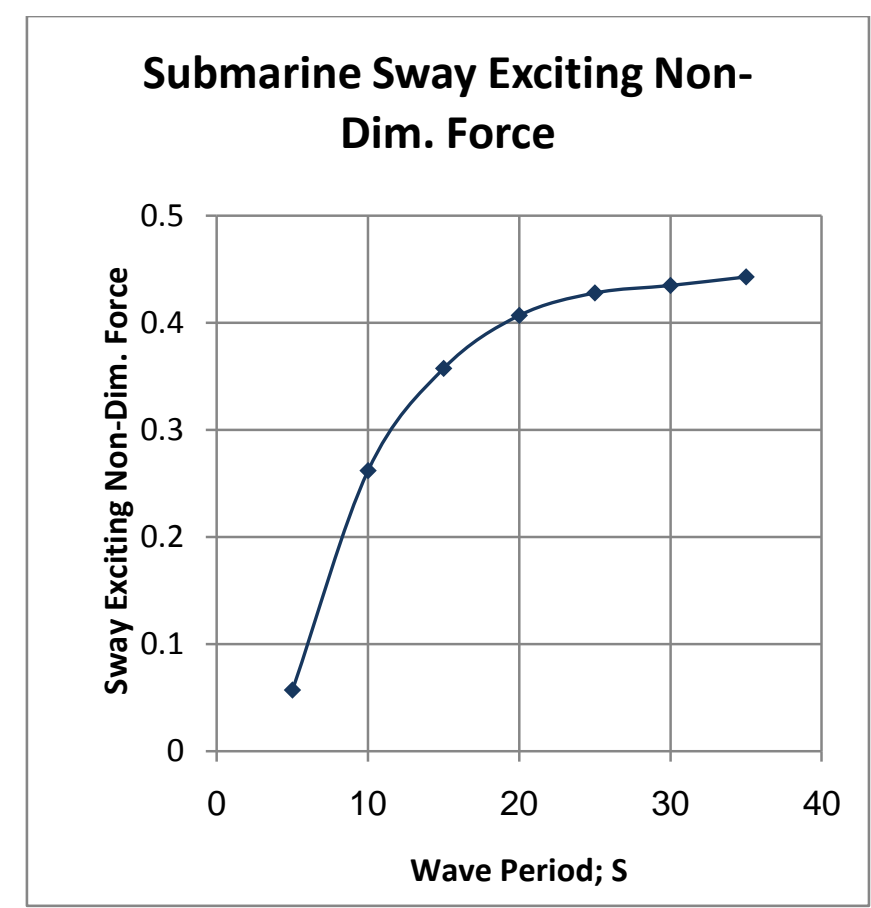

Figure (6): Submarine sway exciting non-dim. force, in beam sea, using present approach.

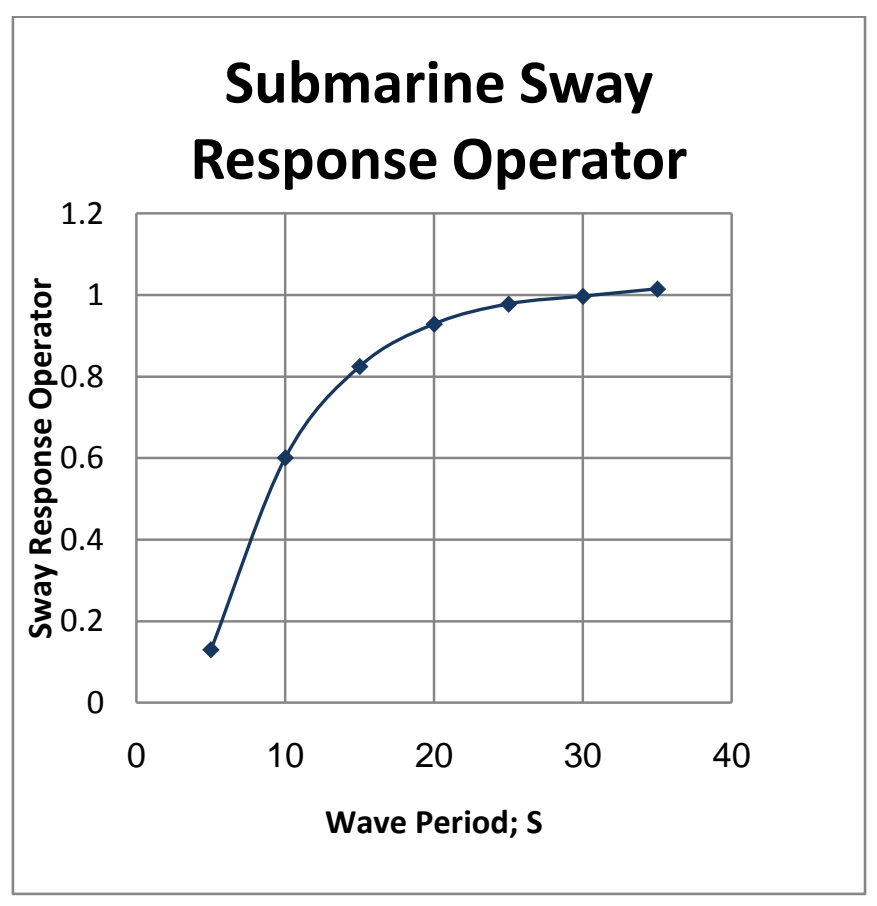

Figure (7): Submarine sway response operator, in beamsea, using present approach.

\section{Submarine Non-Dim. Induced Rolling Mt.}

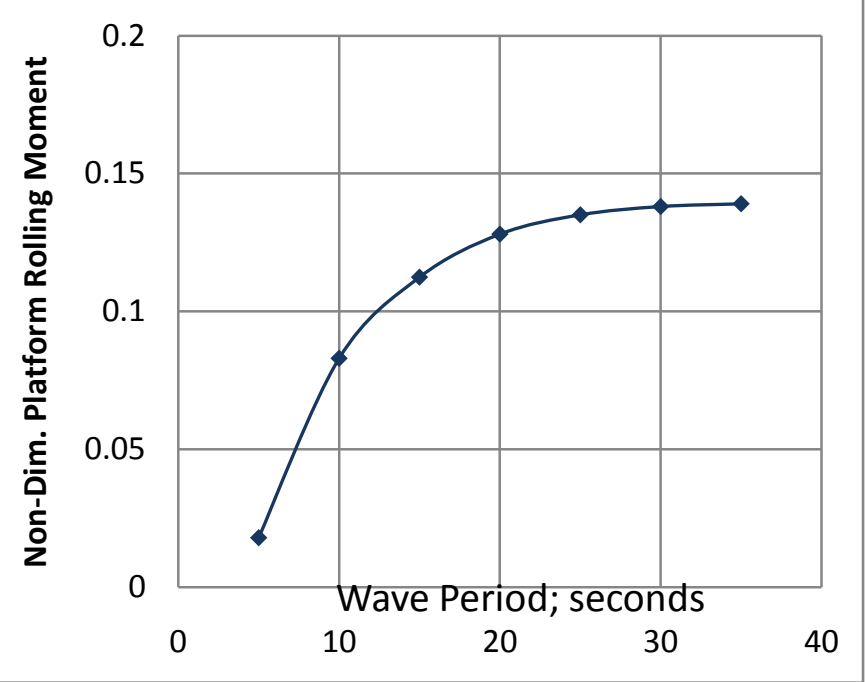

Figure (8): Submarine total non-dim. Roll exciting Moment in beam-sea, present approach.

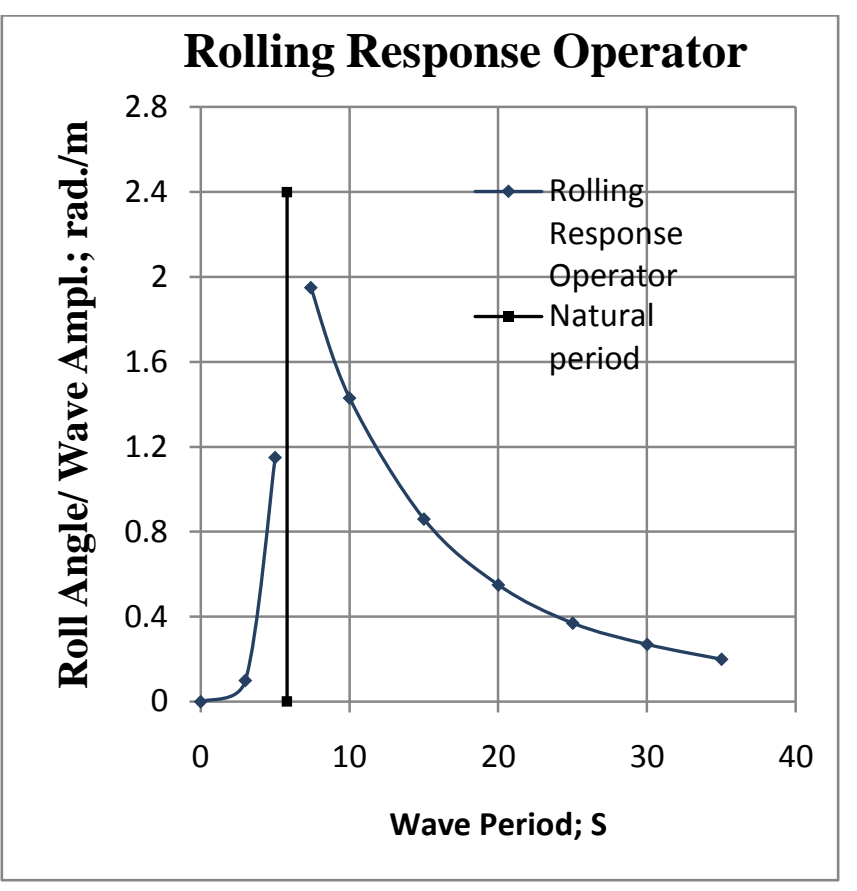

Figure (9): Submarine rolling response operator in beamsea using the present approach. 